What then can we learn from this story and how can we move the field of new drug development in refractory asthma forward? One obvious but important and often overlooked priority is to study the correct patient population and choose the right outcome measure. Thus if one is investigating an anti-eosinophil treatment, it makes sense to begin investigation in a population with severe eosinophilic airway inflammation and choose an inflammation related outcome measure such as exacerbation frequency. In contrast, if the major effects of the investigational agent are on airway smooth muscle function (as seems to be the case with anti-TNF $\alpha$ treatment), then a better population would be those with severe and corticosteroid resistant airway dysfunction, and better outcome measures would be symptoms, variable airflow obstruction and airway hyperresponsiveness. Another important priority is to identify biomarkers of treatment response. In our initial study the beneficial effects of etanercept were closely related to peripheral blood mononuclear cell membrane TNF $\alpha$ expression. ${ }^{21}$ Whether this biomarker can be used to identify a population where anti-TNF $\alpha$ treatment can be used effectively and safely should be investigated.

At a later stage in development, or if the main effects of the investigational agent are unclear, then it is important to evaluate a sufficiently large and well characterised population for relationships between baseline demographics, potential biomarkers and treatments response to be identified. Considerable thought should be put into recruitment criteria with the emphasis more on identifying and including the at need population and less on recruiting a pure population based on arbitrary clinical and physiological criteria. If we can do this, we will learn more about the pathophysiology and heterogeneity of refractory asthma and we may have more to offer a group of patients who currently have considerable unmet needs.

\section{Competing interests: None.}

Thorax 2008;63:571-572. doi:10.1136/thx.2007.095042

\section{REFERENCES}

1. Loddenkemper R, Gibson GJ, Sibille Y. Asthma burden. In: Loddenkemper R, ed. European lung white book. Sheffield: European Respiratory Society, 2003:16-25.

2. Chung KF, Godard P, Adelroth E, et al. Difficult/ therapy-resistant asthma: the need for an integrated approach to define clinical phenotypes, evaluate risk factors, understand pathophysiology and find novel therapies. ERS Task Force on Difficult/TherapyResistant Asthma. European Respiratory Society. Eur Respir J 1999;13:1198-208.

3. American Thoracic Society. Proceedings of the ATS workshop on refractory asthma: current understanding, recommendations, and unanswered questions. Am J Respir Crit Care Med 2000;162:2341-51.

4. Heaney LG, Robinson DS. Severe asthma treatment: need for characterising patients. Lancet 2005;365:974-6

5. Heffler E, Berry M, Pavord ID. Tumor necrosis factoralpha: a promising therapeutic target for asthma? BioDrugs 2007;21:345-9.

6. Cazzola M, Polosa R. Anti-TNF-alpha and Th1 cytokinedirected therapies for the treatment of asthma. Curr Opin Allergy Clin Immunol 2006;6:43-50.

7. Churg A, Dai J, Tai H, et al. Tumor necrosis factoralpha is central to acute cigarette smoke-induced inflammation and connective tissue breakdown. Am J Respir Crit Care Med 2002;166:849-54

8. O'Malley WE, Achinstein B, Shear MJ. Journal of the National Cancer Institute, Vol. 29, 1962: Action of bacterial polysaccharide on tumors. II. Damage of sarcoma 37 by serum of mice treated with Serratia marcescens polysaccharide, and induced tolerance. Nutr Rev 1988:46:389-91.

9. Hotamisligil GS. The role of TNFalpha and TNF receptors in obesity and insulin resistance. $J$ Intern Med 1999;245:621-5

10. Reed CE, Milton DK. Endotoxin-stimulated innate immunity: A contributing factor for asthma. J Allergy Clin Immunol 2001;108:157-66.

11. Howarth PH, Babu KS, Arshad HS, et al. Tumour necrosis factor (TNFalpha) as a novel therapeutic target in symptomatic corticosteroid dependent asthma. Thorax 2005;60:1012-18.

12. Berry MA, Hargadon B, Shelley M, et al. Evidence of a role of tumor necrosis factor alpha in refractory asthma. N Engl J Med 2006;354:697-708.

13. Thomas PS, Heywood G. Effects of inhaled tumour necrosis factor alpha in subjects with mild asthma. Thorax 2002;57:774-8

14. Thomas PS, Yates DH, Barnes PJ. Tumor necrosis factor-alpha increases airway responsiveness and sputum neutrophilia in normal human subjects. Am J Respir Crit Care Med 1995;152:76-80.

15. Amrani Y, Martinet N, Bronner C. Potentiation by tumour necrosis factor-alpha of calcium signals induced by bradykinin and carbachol in human tracheal smooth muscle cells. Br J Pharmacol 1995;114:4-5.

16. Berry MA, Hargadon B, Shelley M, et al. Evidence of a role of tumor necrosis factor alpha in refractory asthma. N Engl J Med 2006;354:697-708.

17. Howarth PH, Babu KS, Arshad HS, et al. Tumour necrosis factor (TNFalpha) as a novel therapeutic target in symptomatic corticosteroid dependent asthma. Thorax 2005;60:1012-18.

18. Berry MA, Hargadon B, Shelley M, et al. Evidence of a role of tumor necrosis factor alpha in refractory asthma. N Engl J Med 2006;354:697-708.

19. Erin EM, Leaker BR, Nicholson GC, et al. The effects of a monoclonal antibody directed against tumor necrosis factor-alpha in asthma. Am J Respir Crit Care Med 2006;174:753-62.

20. Morjaria JB, Chauhan AJ, Babu KS, et al. The role of a soluble TNF $\alpha$ receptor fusion protein (etanercept) in corticosteroid refractory asthma: a double blind randomised, placebo controlled trial. Thorax 2008:63:584-91.

21. Berry MA, Hargadon B, Shelley M, et al. Evidence of a role of tumor necrosis factor alpha in refractory asthma. N Engl J Med 2006;354:697-708.

\title{
Pleurodesis for malignant pleural effusion: talc, toxicity and where next?
}

\section{Helen E Davies, ${ }^{1}$ Y C Gary Lee, ${ }^{1,2}$ Robert J 0 Davies $^{1}$}

Malignant pleural effusion accounts for $22 \%$ of all pleural effusions, and affects about 300000 patients annually (UK and

\footnotetext{
${ }^{1}$ Oxford Pleural Disease Unit, Oxford Centre for Respiratory Medicine and University of Oxford, Oxford, UK; ${ }^{2}$ Centre for Respiratory Research, University College London, London, UK
}

Correspondence to: Dr Robert J 0 Davies, Oxford Centre for Respiratory Medicine, Churchill Hospital, Oxford 0X3 7LJ, UK; robert.davies@ndm.ox.ac.uk
USA). Approximately $50 \%$ of patients with breast cancer, $25 \%$ of those with lung cancer and $>90 \%$ with pleural mesothelioma develop a symptomatic malignant pleural effusion. Thoracentesis provides effective short term symptomatic relief but most large malignant pleural effusions recur, ${ }^{1}$ and pleurodesis is then the standard treatment. A wide range of compounds have been used as pleurodesing agents, but talc is preferred by the majority of respiratory physicians worldwide. $^{2}$

The Medicines and Healthcare Products Regulatory Authority (MHRA) has recently completed an urgent review of the safety of talc as a pleurodesis agent for malignant effusion, reclassifying it as a medicinal product rather than medical device. ${ }^{3}$ This review requires that from January 2008, manufacturers must submit regulatory data if they wish their talc preparation to be used for pleurodesis. This is a milestone on the path towards improved care for malignant effusion as it heralds the first time an agent for intrapleural administration will be regulated under the systems used for biologically active drugs.

Talc is a magnesium silicate hydroxide $\left(\mathrm{Mg}_{3}\left(\mathrm{Si}_{2} \mathrm{O}_{5}\right)_{2}(\mathrm{OH})_{2}\right)$ and is mined, milled and sterilised prior to clinical use, although 
these processes still sometimes leave behind mineral or organic contaminants. The MHRA review was a response to evidence that some of the preparations produced by these processes, and considered safe for pleurodesis in the UK and USA for over 50 years, are in fact anything but. Pleurodesis preparations not sorted to remove most of the smallest talc particles (widely used in the UK and USA) are associated with clinically important hypoxaemia in humans, ${ }^{4}$ induce systemic and pulmonary inflammation after being absorbed from the pleural space ${ }^{5-7}$ and were associated with death from respiratory failure in over $2 \%$ of patients when used for pleurodesis in a large US clinical trial. ${ }^{8}$ Preparations with the smallest talc particles removed (graded talc) are associated with a reduction in this risk. In a European cohort study of 558 patients treated with graded talc, no frank episodes of acute respiratory distress syndrome occurred. Assuming that it is small talc particles which are truly causal of acute respiratory distress syndrome (and not, for example, contaminants) changing to graded talc may avert up to 250 unnecessary deaths each year-a significant improvement in care.

The lesson that intrapleural therapies can cause unexpected systemic toxicity and needs to be thoroughly assessed to ensure safety is not limited to talc. Intrapleural iodopovidone, for example, can cause visual loss $^{9}$ as well as severe chest pain and hypotension. ${ }^{10}$

\section{WHERE NOW FOR TALC?}

Despite the substantial safety improvement that will follow the use of graded talc, some residual questions about safety still remain. Even in the European cohort study $^{11}$ - seen as the strongest evidence of graded talc safety $-7 / 558(\sim 1.5 \%)$ patients developed radiographic pulmonary infiltrate after talc administration. There was also a general increase in post-procedure oxygen requirements, which is consistent with the hypoxaemia seen in a subset of subjects after graded talc administration in human physiological studies. ${ }^{4}$ This hypoxaemia is despite the procedure being one in which substantial pleural effusions are drained, and improvement in respiratory function would be expected. These pointers hint at some residual pulmonary toxicity despite removal of most small size talc particles, and imply that vigilance for talc associated lung inflammation should be maintained in the future.

The "post-marketing" adverse event monitoring for talc will be regulated by the usual drug monitoring systems. This will encourage the highest standards of quality control as licensing will require the achievement of prespecified product standards. For talc, this seems likely to include levels of impurities and particle size. Achieving these standards will probably raise manufacturing expenditure and alter the balance of market forces, increasing the cost of "medical grade talc" in clinical use. This is the inevitable price of higher quality patient care.

\section{WHERE TO FROM HERE?}

The focus these changes will bring to pleurodesis may also spur the search for new and better pleurodesis agents. The development of pleural symphysis is a multifactorial pathway with initial inflammation and subsequent fibrosis which obliterates the pleural space. Strategies to target specific cellular mediators of the pleural inflammatory cascade are already beginning to translate into clinical trials, and efforts focusing on the development of pleural fibrosis without inflammation are ongoing.

In animal studies, intrapleural preparations of the potent profibrotic cytokine transforming growth factor $\beta$ produce an effective pleurodesis. ${ }^{12-15}$ Human trials of this agent are awaited. Less selectively, several bacterial proinflammatory moieties are being explored in an attempt to therapeutically mimic the potent pleural fibrosis induced by bacterial infection. OK-432 1617 (derived from Streptococcus pyogenes) has been used in Asia for several decades, although experience of its use elsewhere is limited. Staphylococcus aureus superantigen, ${ }^{18}$ and motifs derived from other gram positive bacterial cell walls, have both entered early clinical trials, although definitive studies to define their efficacy and toxicity are awaited.

\section{IS AN ENTIRELY DIFFERENT THERAPEUTIC APPROACH WARRANTED?}

If an ideal pleurodesis agent that is capable of effectively controlling fluid and free from significant adverse effects does not exist, it seems reasonable to consider entirely different management strategies for malignant effusion, and to reconsider the definition of "successful" treatment. Clinical trials have tended to focus on pleural fluid recurrence or the extent of pleural symphysis as surrogate markers of success. However, breathlessness relief, and maintaining patients' quality of life, is actually the aim of care for these patients, and this should be the clinical trial outcome of choice.

Subcutaneously tunnelled, indwelling pleural catheters are an accepted component of care for patients with symptomatic effusions who have failed pleurodesis, or where the lung is incapable of re-expansion. ${ }^{19}$ The firstline use of such a type of catheter could permit entirely outpatient care and patient controlled fluid drainage, albeit at the cost of the catheter and drainage equipment, and potential adverse events associated with the presence of the catheter. Initial early and effective fluid drainage may also reduce the likelihood of the development of multi-septated symptomatic and difficult to evacuate effusions, which can be the result of ineffective chemical pleurodesis. Spontaneous pleurodesis rates of up to $70 \%{ }^{20}$ following use of these catheters have been reported in nonrandomised data, and patients' quality of life/sense of empowerment may also improve as a result of this approach. ${ }^{21-23} \mathrm{~A}$ British Lung Foundation funded clinical trial is currently addressing some of these issues and comparing the efficacy and safety of patient controlled fluid drainage by indwelling pleural catheter with standard care.

Other non-pleurodesis based options include use of a pleuroperitoneal shunt, although the need for surgical insertion and potential shunt occlusion are disadvantages to this strategy. Surgical pleurodesis (ie, parietal pleurectomy and pleural abrasion) is effective although limited to patients of exceptionally good performance status and prognosis.

\section{CONCLUSION}

Reclassification of talc for pleurodesis as a drug is a positive step. It is likely to directly improve the safety of talc pleurodesis by influencing particle size and impurity levels, and bringing it in line with all other human medicinal products. The talc debate may also spur the development of new, better pleurodesis agents, and perhaps the complete reshaping of some aspects of care for malignant pleural effusion.

Competing interests: RJOD and HED hold/have an interest in the patent rights for the use of lipoteichoic acid- t for pleurodesis, and Rocket Medical have donated indwelling catheters to a BLF funded clinical trial assessing this therapy that is led from the Oxford Pleural Unit.

Thorax 2008;63:572-574. doi:10.1136/thx.2007.092940

\section{REFERENCES}

1. Anderson CB, Philpott GW, Ferguson TB. The treatment of malignant pleural effusions. Cancer 1974;33:916-22.

2. Lee YC, Baumann MH, Maskell NA, et al. Pleurodesis practice for malignant pleural effusions in five Englishspeaking countries: survey of pulmonologists. Chest 2003;124:2229-38.

3. Medical and Healthcare Products Regulatory Authority (MRHA). MHRA Statement on Talc Preparations for Pleurodesis. Ref: MDR 10-10/07 London: MRHA, 2007. 
4. Maskell NA, Lee YC, Gleeson FV, et al. Randomized trials describing lung inflammation after pleurodesis with talc of varying particle size. Am J Respir Crit Care Med 2004:170:377-82

5. Ferrer J, Montes JF, Villarino MA, et al. Influence of particle size on extrapleural talc dissemination after talc slurry pleurodesis. Chest 2002:122:1018-27.

6. Kennedy L, Harley RA, Sahn SA, et al. Talc slurry pleurodesis. Pleural fluid and histologic analysis. Chest 1995; 107:1707-12.

7. Werebe EC, Pazetti R, Milanez DC Jr, et al. Systemic distribution of talc after intrapleural administration in rats. Chest 1999;115:190-3.

8. Dresler CM, Olak J, Herndon JE, et al. Phase III intergroup study of talc poudrage vs talc slurry sclerosis for malignant pleural effusion. Chest 2005;127:909-15.

9. Wagenfeld L, Zeitz O, Richard G. Visual loss after povidone-iodine pleurodesis. N Engl J Med 2007;357:1264-5.

10. Olivares-Torres CA, Laniado-Laborin R, ChavezGarcia C, et al. lodopovidone pleurodesis for recurrent pleural effusions. Chest 2002;122:581-3.

11. Janssen JP, Collier G, Astoul P, et al. Safety of pleurodesis with talc poudrage in malignant pleural effusion: a prospective cohort study. Lancet 2007;369:1535-9.

12. Lee YC, Teixeira LR, Devin CJ, et al. Transforming growth factor-beta2 induces pleurodesis significantly faster than talc. Am J Respir Crit Care Med 2001;163:640-4.

13. Lee YC, Lane KB, Parker RE, et al. Transforming growth factor beta(2) (TGF beta(2)) produces effective pleurodesis in sheep with no systemic complications. Thorax 2000;55:1058-62.

14. Lee YC, Yasay JR, Johnson JE, et al. Comparing transforming growth factor-beta2, talc and bleomycin as pleurodesing agents in sheep. Respirology 2002; 7:209-16.

15. Light RW, Cheng DS, Lee $\mathrm{YC}$, et al. A single intrapleural injection of transforming growth factorbeta(2) produces an excellent pleurodesis in rabbits Am J Respir Crit Care Med 2000;162:98-104.

16. Kishi K, Homma S, Sakamoto S, et al. Efficacious pleurodesis with OK-432 and doxorubicin against malignant pleural effusions. Eur Respir J 2004;24:263-6.

17. Luh KT, Yang PC, Kuo SH, et al. Comparison of OK432 and mitomycin $\mathrm{C}$ pleurodesis for malignant pleural effusion caused by lung cancer. A randomized trial. Cancer 1992;69:674-9.

18. Ren S, Terman DS, Bohach G, et al. Intrapleura staphylococcal superantigen induces resolution of malignant pleural effusions and a survival benefit in non-small cell lung cancer. Chest 2004:126:1529-39.

19. Tremblay A.Michaud G. Single-center experience with 250 tunnelled pleural catheter insertions for malignant pleural effusion. Chest 2006;129:362-8.

20. Tremblay A, Mason C, Michaud G. Use of tunnelled catheters for malignant pleural effusions in patients fit for pleurodesis. Eur Respir J 2007;30:759-62.

21. Musani Al, Haas AR, Seijo L, et al. Outpatient management of malignant pleural effusions with small-bore, tunneled pleural catheters. Respiration 2004;71:559-66.

22. Putnam JB Jr, Walsh GL, Swisher SG, et al. Outpatient management of malignant pleural effusion by a chronic indwelling pleural catheter. Ann Thorac Surg 2000:69:369-75.

23. Saffran L, Ost DE, Fein AM, et al. Outpatient pleurodesis of malignant pleural effusions using a small-bore pigtail catheter. Chest 2000;118:417-21.

\title{
Are we understanding the respiratory effects of traffic related airborne particles?
}

\author{
Francesco Forastiere, Annunziata Faustini
}

There is convincing scientific evidence showing that ambient particulate matter (PM) is related to both short and long term health effects. Increased mortality and hospitalisation for cardiopulmonary causes have been noted in several studies evaluating the effects of $\mathrm{PM}_{10}$ or $\mathrm{PM}_{2.5}$ (PM $<10$ or $2.5 \mu \mathrm{m}$ in diameter). ${ }^{1}$ However, urban air pollution consists of a complex mixture of gases and particulate agents that vary over time and through space, depending on its sources, distance and meteorological conditions. ${ }^{2}$ Much of the scientific interest has been devoted to the toxicology of the ultrafine fraction of airborne particles $(<0.1 \mu \mathrm{m}){ }^{3}$ These particles are usually emitted from combustion sources (eg, gasoline or diesel powered engines) or are formed from chemical conversion of gases in the atmosphere. They are relatively short lived and combine into larger particles between 0.1 and about $1 \mu \mathrm{m}$ in diameter (accumulation mode). These particles tend to penetrate deeper in the alveolar part of

Department of Epidemiology, Rome E Health Authority, Rome, Italy

Correspondence to: Dr Francesco Forastiere,

Department of Epidemiology, Rome E Health Authority, Via Santa Costanza 53, 00198 Rome, Italy; forastiere@ asplazio.it the lung and have a larger surface area than larger sized particles, eliciting greater potential interaction with human tissues and a stronger inflammatory reaction. The epidemiological evidence linking ultrafine particles with respiratory health effects is still limited and controversial. In the current issue of Thorax, Halonen and colleagues $^{4}$ provide new and compelling evidence on the respiratory effects of particles of various sizes that will certainly stimulate further research (see page 635).

Different sized particles were measured daily in Helsinki over a period of 7 years, and a source apportionment method was applied to separate the $\mathrm{PM}_{2.5}$ fraction from four sources (traffic, long range transport, soil and road dust, and coal/ oil combustion). Daily counts of asthma emergency room visits among children, and asthma/chronic obstructive pulmonary disease (COPD) emergency room visits among adults and the elderly were collected. After careful control for time varying confounding factors, ultrafine particles, $\mathrm{CO}$ and $\mathrm{NO}_{2}$ were strongly associated with asthma in children with a delay of 3-5 days. In contrast, asthma and COPD in the elderly were clearly associated with larger particles (accumulation mode, $\mathrm{PM}_{2.5}$, coarse particles), and
$\mathrm{CO}$ and $\mathrm{NO}_{2}$ at immediate lag (same day). Traffic related particles had a strong delayed effect on children's emergency room visits for asthma whereas traffic related and long range transported particles had an immediate effect on asthma/ COPD visits of the elderly.

There are several strengths of the paper: a new approach to study the effect of air pollution that combines specificity in the exposure assessment (daily measurements with a differential mobility particle sizer), consideration of the pollution sources and specificity in the age groups corresponding to different respiratory conditions. The authors also give interesting indications for understanding the toxicology of particulate matter. Two aspects need to be discussed in light of the differences between asthma and COPD regarding their baseline obstructive and inflammatory characteristics: the timing of the effects that characterise the response to air pollutants in patients with asthma and in COPD patients, and the difference in the size of the particles eliciting the effects.

Childhood asthma is characterised by reversible airflow obstruction, bronchial hyperresponsiveness and an underlying inflammation. The study by Halonen and colleagues ${ }^{4}$ stresses the delayed role of ultrafine particles on this condition. There are other epidemiological observations with similar findings. Two time series studies on emergency room visits or hospitalisations for childhood asthma in the USA ${ }^{5}$ and Copenhagen ${ }^{6}$ support the delayed effect of ultrafine particles. The delayed effects found in these studies, including the Finnish investigation, apparently are at odds with recent 